\title{
Applying STOPP Guidelines in Primary Care Through Electronic Medical Record Decision Support: Randomized Control Trial Highlighting the Importance of Data Quality
}

Morgan Price ${ }^{1,2}$, MD, PhD, CCFP, FCFP; Iryna Davies ${ }^{1}$, MSc; Raymond Rusk ${ }^{1}$, PhD; Mary Lesperance ${ }^{2}$, PhD; Jens Weber ${ }^{1,2}$, PEng, PhD

${ }^{1}$ LEAD Lab, Department of Family Practice, Island Medical Program, University of British Columbia, Victoria, BC, Canada

${ }^{2}$ University of Victoria, Victoria, BC, Canada

Corresponding Author:

Morgan Price, MD, PhD, CCFP, FCFP

LEAD Lab

Department of Family Practice, Island Medical Program

University of British Columbia

Medical Science Building University of Victoria PO Box 1700 STN CSC

Victoria, BC, V8W 2Y2

Canada

Phone: 12502167709

Fax: 12504725505

Email: morgan@leadlab.ca

\section{Abstract}

Background: Potentially Inappropriate Prescriptions (PIPs) are a common cause of morbidity, particularly in the elderly.

Objective: We sought to understand how the Screening Tool of Older People's Prescriptions (STOPP) prescribing criteria, implemented in a routinely used primary care Electronic Medical Record (EMR), could impact PIP rates in community (non-academic) primary care practices.

Methods: We conducted a mixed-method, pragmatic, cluster, randomized control trial in research naïve primary care practices. Phase 1: In the randomized controlled trial, 40 fully automated STOPP rules were implemented as EMR alerts during a 16-week intervention period. The control group did not receive the 40 STOPP rules (but received other alerts). Participants were recruited through the OSCAR EMR user group mailing list and in person at user group meetings. Results were assessed by querying EMR data PIPs. EMR data quality probes were included. Phase 2: physicians were invited to participate in 1-hour semi-structured interviews to discuss the results.

Results: In the EMR, 40 STOPP rules were successfully implemented. Phase 1: A total of 28 physicians from 8 practices were recruited (16 in intervention and 12 in control groups). The calculated PIP rate was 2.6\% (138/5308) (control) and 4.11\% $(768 / 18,668)$ (intervention) at baseline. No change in PIPs was observed through the intervention $(\mathrm{P}=.80)$. Data quality probes generally showed low use of problem list and medication list. Phase 2: A total of 5 physicians participated. All the participants felt that they were aware of the alerts but commented on workflow and presentation challenges.

Conclusions: The calculated PIP rate was markedly less than the expected rate found in literature $(2.6 \%$ and $4.0 \%$ vs $20 \%$ in literature). Data quality probes highlighted issues related to completeness of data in areas of the EMR used for PIP reporting and by the decision support such as problem and medication lists. Users also highlighted areas for better integration of STOPP guidelines with prescribing workflows. Many of the STOPP criteria can be implemented in EMRs using simple logic. However, data quality in EMRs continues to be a challenge and was a limiting step in the effectiveness of the decision support in this study. This is important as decision makers continue to fund implementation and adoption of EMRs with the expectation of the use of advanced tools (such as decision support) without ongoing review of data quality and improvement.

Trial Registration: Clinicaltrials.gov NCT02130895; https://clinicaltrials.gov/ct2/show/NCT02130895 (Archived by WebCite at http://www.webcitation.org/6qyFigSYT) 


\section{KEYWORDS}

electronic medical records; clinical decision support; randomized control trial; electronic prescribing; data quality

\section{Introduction}

\section{Potentially Inappropriate Prescriptions}

Adverse Drug Events (ADEs), injuries, and deaths resulting from the administration of a medication [1-3], are a leading cause of iatrogenic morbidity and mortality. Canadian adverse event rates are estimated at 185,000 annually, with 70,000 being potentially preventable $[4,5]$. The ADE rates are similar in the United States, with the Institute of Medicine estimating that 100,000 preventable deaths occur per year in the United States [6,7]. Medication errors have a greater impact on vulnerable populations such as the elderly, who have significant illness burdens and are often taking a number of medications [8]. It has been reported that $27 \%$ of the elderly are on 5 or more medications [8]. The cost of ADEs in seniors is high: over Can \$35 million annually in Canada [9]. Avoiding inappropriate prescriptions is one important approach to avoiding predictable ADEs among older people [10]. Effective prevention should involve primary care.

\section{Criteria for the Screening Tool of Older People's Prescriptions}

Several groups have attempted to reduce inappropriate prescriptions for the elderly, creating a number of guidelines and criteria to help prescribers use a rational approach to drug prescriptions for the elderly [11]. The Beers criteria [12-16] were developed to support clinicians, and more recently, the STOPP criteria (screening tool of older people's prescriptions) have been developed [17,18]. The STOPP criteria [17-19] consist of 65 recommendations (114 in version 2 [19]) that support evidence-based, individualized prescribing practices among patients 65 and over. The criteria take into account a range of salient patient features to predict potentially inappropriate prescriptions. A systematic review showed that STOPP version 1 was more sensitive than Beers in identifying inappropriate prescribing [11]. The majority of STOPP literature is focused on long-term care and hospital settings [12,14-16,20]. Less work has been done with STOPP in primary care [21,22], even though preventable ADEs are common and serious in this setting [4,23]. In response, this study set out to measure the impact of using the STOPP criteria in primary care, where the majority of prescriptions occur.

\section{Promise of Decision Support}

Clinical Decision Support (CDS) aids clinicians and patients in making appropriate decisions in care. In primary care, CDS is often embedded into Electronic Medical Records (EMRs). There is promise for CDS in improving quality of care in general and prescribing in particular, with $66 \%$ of studies on prescribing systems showing positive outcomes [24]. Although there is promise in these tools, the benefits of using these tools are not consistently realized [25,26]. Studies, such as the MOXXI study, have shown variable responses to CDS for prescribing [27]. In some cases, the user experience of CDS tools is poor enough that alerts are overridden $[1,3]$, the use of CDS and electronic tools have facilitated errors [4], or the CDS tools have had unintended consequences [28,29]. There is a pressing need to improve decision support tools for providers in order to better realize the expected benefits and reduce serious, unintended consequences.

Achieving impact with CDS tools is not without challenges. There are many "grand challenges" for CDS [30] such as development of content, making content available through Web-based systems, and user experience. The American Medical Informatics Association's position paper on CDS design recommends CDS tools that better summarize and prioritize recommendations to reduce the cognitive burden on clinicians and maintain efficiency [31]. SAFER guidelines have been developed to "empower organizations to work with internal or external stakeholders on optimizing [EMR] functionality" [32]. Data quality is often discussed in terms of data use in research [33]; however, data quality is also foundational to CDS [34].

\section{Research Objective}

Through this mixed-method study, we sought to answer the following overarching question:

How can an existing clinical decision support tool implement a complex set of evidence-based rules into primary care clinical practice and how does this impact prescribing?

We considered this question in the context of a primary care EMR with CDS. The EMR was able to be populated by a Web-based decision support application to provide rules. We sought to understand the answers to the question through a combination of EMR data quality probes and participant interviews.

\section{Methods}

This was a mixed-method study divided into two phases: (1) A randomized control trial and (2) A qualitative reflection by participants on the results.

\section{Phase 1: Pragmatic Randomized Control Trial}

Phase 1 was a prospective, intention-to-treat, un-blinded, cluster randomized trial. The primary outcome measure was the change in rate of STOPP-defined PIPs as documented in the OSCAR EMR in the intervention group as compared with the control group.

\section{Participants}

\section{Inclusion Criteria}

The participants were primary care physicians in British Columbia providing office-based care to patients 65 and over, using the open source OSCAR EMR developed by McMaster University and the OSCAR community (version 12.x) for at least 12 months (this was to provide enough time for medications to be consistently documented in the EMR), and who were part of or willing to be part of the University of British Columbia's Department of Family Practice Research Network. 


\section{Exclusion Criteria}

Providers who do not provide longitudinal care (eg, walk in clinics) or only hospital care, who do not use OSCAR for writing prescriptions, or who provide care to a younger population (eg, a maternity clinic) were excluded from the study.

\section{Sample Size}

Sample size was calculated assuming a PIP rate of $20 \%$ $[10,27,35]$ and an expected relative reduction of $20 \%$ in PIPs (absolute reduction of $4 \%$ ). Using a power of 0.8 and alpha $=0.05$ and estimating that two practices may be lost to follow up, we predicted the need for 12 practices in each arm and 900 encounters per arm with patients 65 years and over.

\section{Recruitment and Randomization}

Providers were recruited through the OSCAR Canada User Society's mailing list and the 2014 OSCAR EMR national user meeting (over 100 people were made aware of the study). Potential participants were screened by the primary investigator on the phone or in person to ensure they met the criteria.

Clinics were randomly assigned (equal distribution by clinic) to the intervention or control groups using a random number generator that generated the list prior to the recruitment and allocation of participants. Randomization was stratified into small ( $<4$ physicians) and large clinics ( $\geq 4$ physicians).

All physicians (in the control and intervention groups) received the same orientation to the purpose of the study, the nature of the STOPP criteria, and what was being measured. The intervention group also received assistance in activating the STOPP criteria in their CDS tools. The control group was invited to have the STOPP guidelines activated after the study and the guidelines were made freely available to the OSCAR community after the study.

\section{Intervention}

The intervention group received the STOPP guidelines content in their EMR, whereas the control group did not. The STOPP guidelines leveraged the existing CDS engine of the EMR. These additional guidelines provided suggestions to the providers when specific criteria were met for an individual patient being seen. The EMR showed patient specific guideline recommendation titles in a text window in the side bar of the patient's chart. These titles could be clicked on for more information (Figure 1).

Implementation at the user level was required in the intervention group and facilitated by one of the authors (ID). Participants were instructed and walked through how to turn on the STOPP rules by trusting the STOPP content in the Clinical Decision Support (CDS) module. This downloaded and activated the STOPP rules for that user for the duration of the trial.

A subset of 40 STOPP rules (that were found in both STOPP v1 and v2) was developed for the EMR CDS rules engine. The rules and the network queries (which measured the outcomes as PIP rates) were generated from the same logic files to ensure consistency between the EMR CDS rules and the network measurements.
The 40 STOPP rules were successfully modeled and implemented for this study. It was not possible to create all STOPP rules due to features in the EMR or network query engine. STOPP rules that were not included contained concepts such as duration of combined prescriptions or dose thresholds that could not be modeled in one of the two components (eg, the EMR guideline logic or the network query). Shortly before the study was to start, version 2 of the STOPP rules were published. Rules from version 1 that were removed in version 2 were removed from our study.

\section{Primary Outcome Measure}

The primary outcome measure was the difference in change in measured PIP rates between the intervention and control groups before the intervention as compared with the difference after the intervention period.

\section{Data Quality Probes}

To provide context and estimate the validity of answers, a set of 13 data quality probes (DQ probes) were created. These assessed the data quality of demographics, medications, and the problem list-the three areas that were in the control of the clinic and related to the STOPP criteria. All DQ probes considered only those patients that had had an encounter at the clinic in the last two years. The DQ probes list is shown in Table 2.

\section{Data Collection}

\section{Phase 1: Collection of Physician Information}

All the participants completed a survey describing their practice at the start of the study.

\section{Measurement of Potentially Inappropriate Prescriptions}

Measurement of PIPs and DQ probes was completed using the UBC Department of Family Practice research network, which was developed with the Physicians Data Collaborative of British Columbia. The network is based on hQuery, an open source tool that is freely available on GitHub. The research network is designed to distribute querying of EMR health data without collection and storage of patient level data. Only aggregate data (ie, summary answers to queries) are collected in the central Hub [36]. Patient privacy was maintained through the network as only practice level aggregate answers were returned through the network.

\section{Baseline Rates of Potentially Inappropriate Prescriptions}

Queries were run at the start of the study for each clinic to provide baseline data of the 16 weeks preceding the study.

Intervention Rates of Potentially Inappropriate Prescriptions

Queries were repeated after the 16-week intervention period to assess PIP rates for the intervention period.

\section{Data Analysis}

PIPs for each of the STOPP rules and DQ probes were measured for each clinic. Statistical regression models (which account for the clustered nature of the data) were fit to assess the primary outcome (geeglm in R package geepack) [37]. 
All clinics received an individualized summary of the findings from the study including PIP rates, most common PIPs in their practice, and highlights of data quality in their EMRs.

\section{Phase 2: Explaining Findings and Understanding Experiences}

Phase 2 consisted of one-hour semistructured interviews with physicians in the intervention group. These reflection sessions encouraged physicians to explain the findings. The findings for the study were shared, including physicians' own clinic specific summaries, and they were asked to reflect on the results and describe their experiences. Participants were invited to provide information on how to improve the tools in the EMR.
This study was registered at clinical trials.gov (NCT02130895) and received clinical ethics approval from the University of British Columbia (H14-00797).

\section{Results}

\section{Participation}

The study was completed from February-October, 2015. A total of 8 clinics were engaged in the study ( 9 were approached, but one declined because of technical reasons with their EMR) and randomization occurred at the clinic level. Twenty-eight physicians across the eight practices consented in person. None were lost to follow up (Figure 2). One participant reported a technical problem with the EMR that was thought to be related to the intervention and later discovered to be unrelated.

Figure 1. Wireframe of the CDS alerts in the EMR. (A) on the right is the panel that lists patient specific alerts. From that panel, users can click a title and get (B), the detail of the alert that pops up when clicked.

\begin{tabular}{llllll} 
Patient Name: Alan IVE & Age: 100 & DoB: 23-Jan-1916 Health\# 9044432321 \\
\hline eCHART & Summary & Medications & Labs & Documents More & Search \\
\hline
\end{tabular}

\begin{tabular}{|c|c|c|}
\hline \multirow{2}{*}{\multicolumn{2}{|c|}{$\begin{array}{l}\text { Lorem ipsum dolor sit amet, consectetur adipisicing elit, sed do eiusmod tempor incididunt } \\
\text { ut labore et dolore magna aliqua. Ut enim ad minim veniam, quis nostrud exercitation } \\
\text { ullamco laboris nisi ut aliquip ex ea commodo consequat. }\end{array}$}} & Problem List \\
\hline & & Congestive Heart Failure \\
\hline \multirow{2}{*}{\multicolumn{2}{|c|}{$\begin{array}{l}\text { Duis aute irure dolor in reprehenderit in voluptate velit esse cillum dolore eu fugiat nulla } \\
\text { pariatur. Excepteur s. } \\
\text { mollit anim id est lal }\end{array}$}} & Diabetes \\
\hline & & Osteroarthritis \\
\hline \multirow{4}{*}{$\begin{array}{l}\text { Lorem ipsum dolor sit ame } \\
\text { ut labore et dolore magna } \\
\text { ullamco laboris nisi ut aliqu } \\
\text { Duis aute irure dolor in rep } \\
\text { pariatur. Excepteur sint oco } \\
\text { mollit anim id est laborum. }\end{array}$} & \multirow{4}{*}{$\begin{array}{l}\text { Consider Avoiding NSAIDs with CHF } \\
\text { Consider avoiding NSAIDs in patients with Congestive } \\
\text { Heart Failure (CHF). NSAIDs can adversely impact } \\
\text { hypertension, electrolyte imbalances, CHF, and kidney } \\
\text { function. NSAID cardiotoxicity is relatively rare, but } \\
\text { increasingly common in the elderly. Thus they should be } \\
\text { considered carefully and perhaps substituted with } \\
\text { acetaminophen or other pain medication / combinations. }\end{array}$} & Medications \\
\hline & & ASA - ASPIRIN - 325 mg - tablet - oral - daily \\
\hline & & $\begin{array}{l}\text { Glucophage - METFORMIN - } 500 \text { mg - tablet - oral - } \\
\text { twice a day }\end{array}$ \\
\hline & & \\
\hline \multirow{2}{*}{$\begin{array}{l}\text { Lorem ipsum dolor sit ame } \\
\text { ut labore et dolore magna } \\
\text { ullamco laboris nisi ut aliquip }\end{array}$} & [Slørdal and Spigest 2006] & \\
\hline & ex ea commodo consequat. & Consider reducing ASA dose \\
\hline \multirow{5}{*}{\multicolumn{2}{|c|}{$\begin{array}{l}\text { Duis aute irure dolor in reprehenderit in voluptate velit esse cillum dolore eu fugiat nulla } \\
\text { pariatur. Excepteur sint occaecat cupidatat non proident, sunt in culpa qui officia deserunt } \\
\text { mollit anim id est laborum. }\end{array}$}} & Consider avoiding NSAIDs with CHF \\
\hline & & Other Sections \\
\hline & & $x x x x x x x x x x x$ \\
\hline & & $x x x x x x x x x x x x$ \\
\hline & & $x x x x x x x x x x x x$ \\
\hline
\end{tabular}


Figure 2. CONSORT figure. 28 physicians in 8 clinics were recruited into the study. 1 clinic declined to participate during recruitment. No clinics or physicians were lost to follow up during the trial.

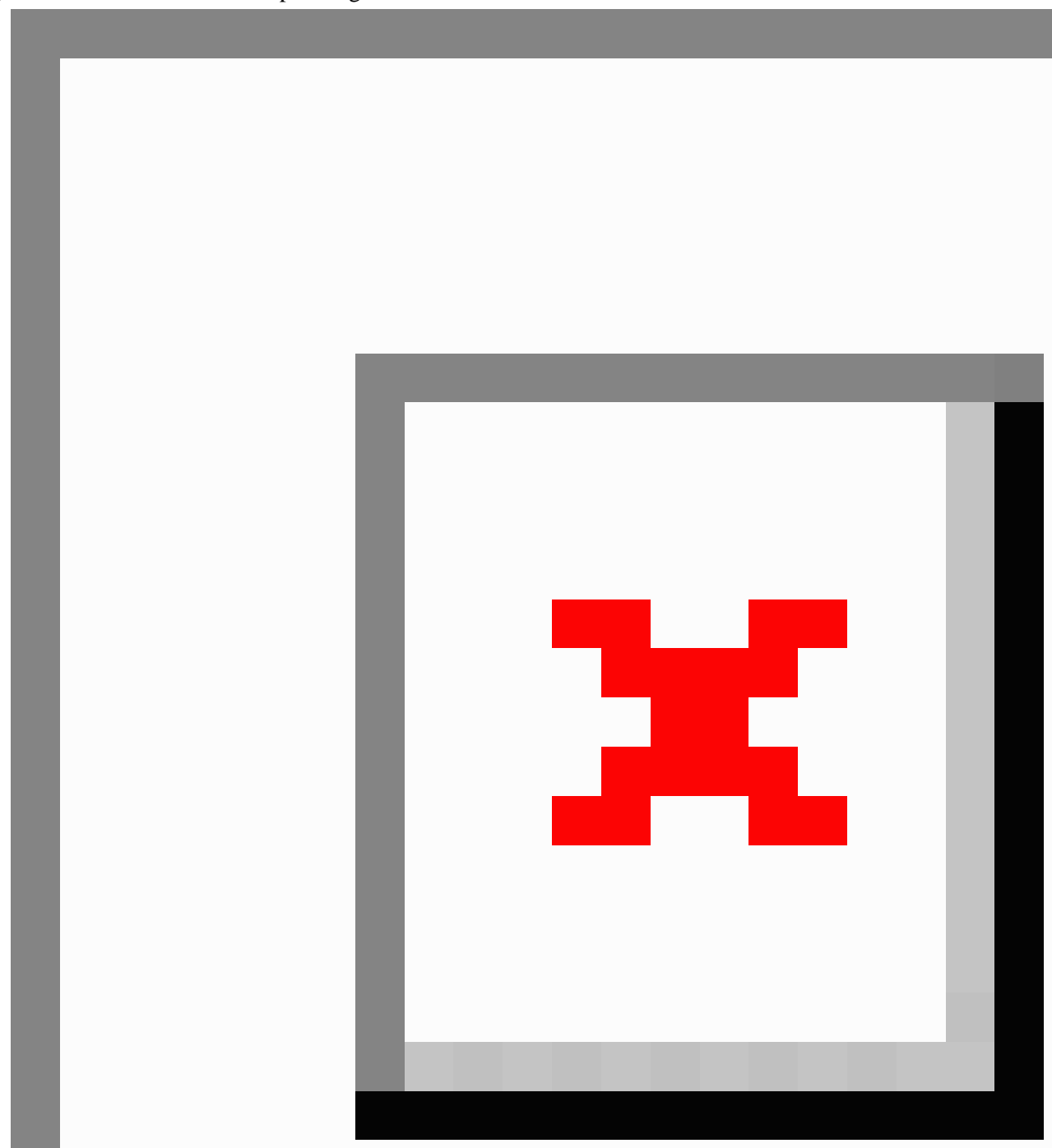

\section{Phase 1 Results}

The control group saw 1086 patients who could have triggered a PIP during the baseline period and 1204 during the treatment period. In the control group, there were 138 PIPs (out of a possible 5308 that could have been triggered) during baseline and 157 PIPs (out of a possible 5792) during treatment.
The intervention group saw 3556 patients who could have triggered a PIP during the baseline period and 3621 during the treatment period. In the intervention group, there were 742 PIPs during baseline (out of a possible 18,331) and 768 PIPs during treatment (out of a possible 18,668). There was an initial difference between the two groups $(2.6 \%$ and $4.0 \%$ of prescriptions were flagged as PIPs in the control and intervention groups, respectively). 
Table 1. Rates of PIPs in the control and intervention groups before and during the treatment periods.

\begin{tabular}{lll}
\hline Rates & Intervention, $\%$ & Control, $\%$ \\
\hline Before treatment (baseline) & 4.0 & 2.6 \\
During treatment & 4.1 & 2.7 \\
Change in potentially inappropriate prescriptions (PIP)rates & 0.1 & 0.1 \\
\hline
\end{tabular}

Both groups saw similar numbers of patients during the study $(44,290$ in the control group and 37,615 in the intervention group); however, the intervention group had a greater proportion of patients who were 65 years and older (control 5\% vs intervention $19 \%$ ).
The regression analysis of PIPs showed no significant difference in change of recorded PIPs in the control group versus the intervention group $(P=.80)$.

Table 2. Data quality probes assessing demographics, medications, and problem list usage.

\begin{tabular}{|c|c|c|}
\hline Data quality probe description & Intervention, $\%$ & Control, \% \\
\hline What percentage of patients, flagged as active, had at least one encounter in the past 24 months? & 35.7 & 28.6 \\
\hline What is the percentage of patients, calculated as active, with no documented gender? & 0.3 & 0.5 \\
\hline What percentage of patients, calculated as active, has an invalid date of birth? & 0.0 & 0.0 \\
\hline What percentage of patients, calculated as active, has no documented date of birth? & 0.0 & 0.0 \\
\hline What percentage of current medications is coded? & 82.3 & 79.0 \\
\hline What percentage of patients, calculated as active, has no current medications? & 69.9 & 84.6 \\
\hline What percentage of problems on the problem list, documented in the past 12 months, has a diagnostic code? & 100.0 & 100.0 \\
\hline $\begin{array}{l}\text { What percentage of patients, aged } 12 \text { years and over and calculated as active, has at least one documented problem } \\
\text { on the problem list (documented in the past } 12 \text { months)? }\end{array}$ & 12.3 & 3.5 \\
\hline What percentage of patients, calculated as active and aged 12 years and over, has Diabetes on the problem list? & 5.3 & 3.5 \\
\hline Of patients currently on Tiotropium medication, what percentage has "COPD",a on the problem list? & 48.1 & 72.7 \\
\hline Of patients currently on Levothyroxine medication, what percentage has "Hypothyroidism" on the problem list? & 22.7 & 24.3 \\
\hline Of patients currently on anti-gout medication, what percentage has "Gout" on the problem list? & 8.4 & 12.2 \\
\hline
\end{tabular}

${ }^{\mathrm{a}}$ COPD: chronic obstructive pulmonary disease.

\section{Data Quality Probes}

EMR data quality was estimated using a set of DQ probes that were executed in the same way as PIP rates were evaluated. The DQ probes were used to assess completeness, correctness, and concordance.

Both groups had a large number of active patients (an average of $68.2 \%$ ) that were documented as active according to the EMR but that had not had an appointment in at least two years. (Note: STOPP queries were designed only to look at patients who had had an encounter during either the baseline or intervention period). We found that $79-82 \%$ of prescriptions were coded, with the remainder being free text; however, there were a high number of patients who were not on any active medications in both groups. All documented problems on the problem list were coded (this was a requirement for the working of the EMR); however, only a small number of patients $(12.3 \%$ in the intervention group and $3.5 \%$ in the control group) had at least one problem on the problem list. In the control group, interestingly, nearly all the patients were also diabetic. The three DQ probes that relate diagnosis to medication use (COPD, hypothyroidism, and gout) all showed that the coded problem list was under-utilized.
The software engineers on this project confirmed the results of the study's queries by using an alternate query method to ensure that the query logic was running correctly. These queries confirmed the above findings.

\section{Phase 2 Findings}

Total of 5 physicians across 3 of the 4 intervention group clinics participated in phase 2 . Two of the participants had discussed the study and the phase 2 interview with their colleagues in preparation for the meeting and shared their collective thoughts. Three themes emerged from the interviews.

\section{Alert Awareness}

All phase 2 participants felt that they were aware of the STOPP alerts (participants were not blinded to being in the intervention group). However, although they all felt that they had seen "some" CDS alerts, they felt they might not have consistently seen them.

\section{Workflow and Display}

The location on screen and the workflow were thought to be barriers. The STOPP criteria, as they had more complex rules, were implemented differently and displayed in a separate location to simple drug alerts. This often meant that the user 
would need to tab between screens and refresh screens. Participants preferred a single location for all medication related alerts, regardless of the logic behind those alerts.

\section{Study Disruptiveness}

Finally, the participants reflected on the disruption caused by the study to their practice. All of them agreed that the disruption caused by this kind of study was minimal and that they would all participate in future studies.

\section{Discussion}

We sought to obtain an answer to the following question:

How can an existing clinical decision support tool implement a complex set of evidence-based rules into primary care clinical practice and how does this impact prescribing?

A total of 40 STOPP criteria were implemented in the primary care EMR. There were some limitations in the CDS module logic that prevented some rules from being implemented, such as being able to calculate the duration for which a patient had been on a medication over multiple prescriptions. However, the randomized trial component of this study was unable to show a significant change in PIPs rates that could be attributed to the STOPP guidelines as implemented. There are at least two reasons for this.

First, the rate of measured PIPs was lower than expected when compared with PIP rates found in the literature [10,27,35]. With measured PIP rates of $2.6 \%$ and $4.0 \%$, it was not possible to see the decrease in PIPs expected from other studies. The DQ probes begin to shed light on why the measured PIP rate is lower than expected. The areas of the EMR that were used by the STOPP rules (eg, the coded problems on the problem list and coded prescriptions that were up to date) were utilized with less frequency than expected and, thus, the CDS rules were not fired as often. For example, we see that $92 \%$ of patients had no diagnosis input into their coded problem list, which is a rate of use that is lower than anticipated. Gaps in EMR data quality are as important today as they were twenty years ago [38]. While electronic medical record data are increasingly available and easy to access, the data quality is increasingly the challenge [39]. This is a key point highlighted by this study that should be considered by implementers and decision makers. Even though this study was completed with people using an established EMR that has been widely adopted in Canada and had been adopted in the participating clinics for some time, the data was not fit for use in the CDS.

Data quality is often talked about in terms of data warehouses [33], connecting multiple systems [40], and big data [41]. This study also highlights that data quality is a limiter when applying computational interventions that are designed to support improvements in care for individual patients. Missing, uncoded, or variably documented (eg, in another location within the EMR) data may well have been the limiter in this study.

Second, the participants in phase 2 discussed some challenges with the CDS. For example, the workflow of the STOPP alerts was less than ideal: for technical reasons, the STOPP rules were presented in the main chart and not in the prescription module.
The guideline tool did not have a clear way to support users in prioritizing suggestions and alerts as recommended [42]. The alerts were positioned near the bottom of the screen and the users felt that, while they were aware of them, they were small, in a list with other reminders, and could potentially be missed.

Despite the negative result, there are still several valuable lessons that can be learned from this pragmatic trial.

\section{Lessons Learned}

\section{Translating Rules for the Screening Tool of Older People's Prescriptions into Electronic Medical Record Algorithms}

In general, the STOPP rules were well specified and computable definitions that could be created for most rules. However, in many cases, definitions had to be refined based on the logic features and data accessible in the EMR. The STOPP rules were not defined using specific medical terminologies (eg, International Classification of Disease (ICD) codes) and these had to be developed for this study. This gap is not unique to STOPP rules; indeed, others have had similar challenges in translating clinical guidelines into computer interpretable rules or alerts [43]. However, we recommend that future versions of STOPP and other recommendations consider using terminologies in their definitions to aid in consistent translation into computable forms. Finally, the CDS engine was not able to access all EMR data elements described in the STOPP criteria and several rules were excluded.

\section{Data Quality}

This was a pragmatic trial. We wanted to see the impact of implementation of CDS in nonacademic practices that had not gone through extensive data quality improvement training. This would better predict impact of CDS tools in real world settings. We discovered that $77 \%$ of patients were not on medications that could be queried. Approximately $20 \%$ of prescriptions were documented in the prescription writer without codes that could be queried, indicating custom medications (ie, free text) that would further limit the ability of the CDS. Over $92 \%$ of patients had no coded problems on the problem list (these were queries of the practice, not just the study population). As these were two data sources for many of the queries, data quality was one of the limiting factors to the triggering of the CDS guidelines. This would likely impact other similar uses of CDS without remediation. The EMR allowed for free text in several places (eg, within encounter notes) and so it would be possible for many more items to be recorded in the EMR than could be queried in a coded manner, if the respective EMR components were not used as intended.

Participants in phase 2 were generally unaware of these data quality issues. Previous work has highlighted that physicians often think of the EMR as an "electronic paper record" [44] and do not consider the downstream impacts of not using or inappropriately using components of the EMR. There is an ongoing need for more general education around the use of EMR and EMR data for primary care physicians. 


\section{EMR Workflow Limitations}

In this study, the EMR could not integrate complex CDS rules into the prescribing module. Thus, STOPP alerts appeared in the main screen of the patient chart. Future implementations should allow for better integration into key workflows, such as prescribing. Furthermore, while the guideline engine did allow for summary and additional information to be displayed on user request, it did not allow for easy actions to be performed (eg, discontinuing a medication that triggered the STOPP guideline). There was an EMR workflow that users could use that would skip the screen where the CDS STOPP rules were displayed; however, participants in phase 2 stated that this was not a typical workflow. This issue has been addressed in an upcoming version of the EMR.

\section{Study Implementation}

One of the guiding principles when developing this study was to implement and run the study with as little disruptive impact on practicing physicians as possible. Feedback from the participants was positive in terms of ease of study participation. However, an important matter to explore in future work is the minimum amount of training needed to achieve sufficient improvements in data quality to achieve benefits from the application of complex rules like STOPP. This has implications not just for future studies but also for the implementation of future CDS as part of EMR requirements and quality improvement initiatives.

\section{EMRs Permit Variable Workflows}

Although we confirmed subjectively through phase 2 interviews that practitioners saw the guidelines and had the opportunity to act, we did not have a mechanism to proactively measure individual workflows in the EMR. It is possible (eg, through quick links for direct medication renewals) to avoid the triggering of the EMR guideline module where the STOPP rules reside. We were not able to measure how often this quick link or other paths might have been used. This information would be helpful in understanding how to redesign the EMR and other clinical information systems in the future.

\section{Embedding Knowledge Translation}

This study was designed with two knowledge translation (KT) partners: the EMR and the research network. The STOPP alerts and network queries were developed with these two groups and the materials were provided to each group freely at the end of the study. This proved to be an effective way of engaging with participants and partners and ensuring that the knowledge and artifacts from the study have future application. It was an excellent model to engage both the partners and the end-users in the study as the providers understood that their participation would allow for greater and ongoing impacts in the community.

\section{Study Limitations}

The study had several limitations, which were as follows. (1) Participants were not blinded to which arm of the study they were in. (2) Physicians and clinics volunteered to participate in the network and the study. (3) Because of the timing of the study, the newest version of the particular EMR was not yet installed for the study clinics. This resulted in using an outdated user interface model. The newer EMR has addressed several workflow issues related to CDS and prescribing. (4) Only 40 STOPP study criteria were implemented. (5) Data quality probes were of a more general nature and not specific to the age range of this study's patient population.

\section{Future Direction}

Data quality is a key issue for the use of CDS tools, especially outside of large academic centers where there may be additional resources to improve data quality. The authors have begun to consider data quality by design as an engineering framework that can be applied in the real world [45]. Given the highlights related to workflow and CDS from this study, current work is exploring new user interface designs that support different paradigms for CDS [46] in prescribing. These design ideas are being shared with EMR vendors. As newer versions of the EMR and other study components are engineered and adopted, repeating the study will allow for some level of comparison to assess the changes in design.

\section{Conclusions}

This pragmatic study intentionally implemented a subset of STOPP prescribing guidelines into nonacademic primary care offices with minimal training and disruption. One of the limitations discovered was the data quality in the EMR databases. The rates of measured potentially inappropriate prescriptions was limited and, thus, the rate at which the decision support would be triggered was limited by insufficient use of the EMR components that were connected to the decision support system. Further, this study provides more evidence to support the need to carefully design the workflows of the EMR tools that will support quality. As decision makers create policy to implement tools in EMRs such as decision support, careful attention will be required to ensure that practices and their data are ready to adopt these tools.

\section{Acknowledgments}

We would like to thank the Canadian Institutes of Health Research that funded this research through the eHealth Catalyst Grant program; the Physicians Data Collaborative of British Columbia; OSCAR-EMR and the OSCAR Canada User Society, who engaged and supported this work; and the UBC Department of Family Practice's practice-based research network.

\section{Conflicts of Interest}

None declared. 


\section{Multimedia Appendix 1}

CONSORT EHealth Checklist (V 1.6.1).

[PDF File (Adobe PDF File), 730KB-Multimedia Appendix 1]

\section{References}

1. Weingart SN, Toth M, Sands DZ, Aronson MD, Davis RB, Phillips RS. Physicians' decisions to override computerized drug alerts in primary care. Arch Intern Med 2003 Nov 24;163(21):2625-2631. [doi: 10.1001/archinte.163.21.2625] [Medline: 14638563]

2. Lazarou J, Pomeranz BH, Corey PN. Incidence of adverse drug reactions in hospitalized patients: a meta-analysis of prospective studies. J Am Med Assoc 1998 Apr 15;279(15):1200-1205. [Medline: 9555760]

3. Shah SGS, Robinson I. Benefits of and barriers to involving users in medical device technology development and evaluation. Int J Technol Assess Health Care 2007;23(1):131-137. [doi: 10.1017/S0266462307051677] [Medline: 17234027]

4. Koppel R, Metlay JP, Cohen A, Abaluck B, Localio AR, Kimmel SE, et al. Role of computerized physician order entry systems in facilitating medication errors. J Am Med Assoc 2005 Mar 9;293(10):1197-1203. [doi: 10.1001/jama.293.10.1197] [Medline: 15755942$]$

5. Baker GR, Norton PG, Flintoft V, Blais R, Brown A, Cox J, et al. The Canadian Adverse Events study: the incidence of adverse events among hospital patients in Canada. CMAJ 2004 May 25;170(11):1678-1686 [FREE Full text] [Medline: $\underline{15159366]}$

6. Richardson WC, Berwick DM, Bisgard JC, Bristow LR, Buck CR, Cassel CK. Crossing the quality chasm: a new health system for the 21st century. Washington, D.C: National Academy Press; 2001.

7. Budnitz DS, Lovegrove MC, Shehab N, Richards CL. Emergency hospitalizations for adverse drug events in older Americans. N Engl J Med 2011 Nov 24;365(21):2002-2012. [doi: 10.1056/NEJMsa1103053] [Medline: 22111719]

8. Reason B, Terner M, Moses MA, Tipper B, Webster G. The impact of polypharmacy on the health of Canadian seniors. Fam Pract 2012 Aug;29(4):427-432. [doi: 10.1093/fampra/cmr124] [Medline: 22223743]

9. Wu C, Bell CM, Wodchis WP. Incidence and economic burden of adverse drug reactions among elderly patients in Ontario emergency departments: a retrospective study. Drug Saf 2012 Sep 01;35(9):769-781 [FREE Full text] [doi: 10.2165/11599540-000000000-00000] [Medline: 22823502]

10. Ryan C, O'Mahony D, Kennedy J, Weedle P, Byrne S. Potentially inappropriate prescribing in an Irish elderly population in primary care. Br J Clin Pharmacol 2009 Dec;68(6):936-947 [FREE Full text] [doi: 10.1111/j.1365-2125.2009.03531.x] [Medline: 20002089]

11. Hill-Taylor B, Sketris I, Hayden J, Byrne S, O'Sullivan D, Christie R. Application of the STOPP/START criteria: a systematic review of the prevalence of potentially inappropriate prescribing in older adults, and evidence of clinical, humanistic and economic impact. J Clin Pharm Ther 2013 Oct;38(5):360-372. [doi: 10.1111/jcpt.12059] [Medline: 23550814]

12. Pyszka LL, Seys RT, Milhans SM. Identification of inappropriate prescribing in geriatrics at a Veterans Affairs hospital using STOPP/START screening tools. Consult Pharm 2010 Jun;25(6):365-373. [doi: 10.4140/TCP.n.2010.365] [Medline: 20534407]

13. By the American Geriatrics Society 2015 Beers Criteria Update Expert Panel. American Geriatrics Society 2015 updated beers criteria for potentially inappropriate medication use in older adults. J Am Geriatr Soc 2015 Nov;63(11):2227-2246. [doi: 10.1111/jgs.13702] [Medline: 26446832]

14. García-Gollarte F, Baleriola-Júlvez J, Ferrero-López I, Cruz-Jentoft AJ. Inappropriate drug prescription at nursing home admission. J Am Med Dir Assoc 2012 Jan;13(1):83.e9-83.15. [doi: 10.1016/j.jamda.2011.02.009] [Medline: 22208763]

15. Liu C, Peng L, Chen Y, Lin M, Liu L, Chen L. Potentially inappropriate prescribing (IP) for elderly medical inpatients in Taiwan: a hospital-based study. Arch Gerontol Geriatr 2012;55(1):148-151. [doi: 10.1016/j.archger.2011.07.001] [Medline: 21820189]

16. Parsons C, Johnston S, Mathie E, Baron N, Machen I, Amador S, et al. Potentially inappropriate prescribing in older people with dementia in care homes: a retrospective analysis. Drugs Aging 2012 Feb 01;29(2):143-155. [doi:

10.2165/11598560-000000000-00000] [Medline: 22204669]

17. Gallagher P, O'Mahony D. STOPP (Screening Tool of Older Persons' potentially inappropriate Prescriptions): application to acutely ill elderly patients and comparison with Beers' criteria. Age Ageing 2008 Nov;37(6):673-679 [FREE Full text] [doi: 10.1093/ageing/afn197] [Medline: 18829684]

18. Gallagher P, Ryan C, Byrne S, Kennedy J, O'Mahony D. STOPP (Screening Tool of Older Person's Prescriptions) and START (Screening Tool to Alert doctors to Right Treatment). Consensus validation. Int J Clin Pharmacol Ther 2008 Feb;46(2):72-83. [Medline: 18218287]

19. O'Mahony D, O'Sullivan D, Byrne S, O'Connor MN, Ryan C, Gallagher P. STOPP/START criteria for potentially inappropriate prescribing in older people: version 2. Age Ageing 2015 Mar;44(2):213-218 [FREE Full text] [doi: 10.1093/ageing/afu145] [Medline: 25324330]

20. Hamilton HJ, Gallagher PF, O'Mahony D. Inappropriate prescribing and adverse drug events in older people. BMC Geriatr 2009 Jan 28;9:5 [FREE Full text] [doi: 10.1186/1471-2318-9-5] [Medline: 19175914] 
21. Yayla ME, Bilge U, Binen E, Keskin A. The use of START/STOPP criteria for elderly patients in primary care. ScientificWorldJournal 2013;2013:165873 [FREE Full text] [doi: 10.1155/2013/165873] [Medline: 23853529]

22. Conejos MM, Sánchez CM, Delgado SE, Sevilla MI, González-Blazquez S, Montero EB. Potentially inappropriate drug prescription in older subjects across health care settings. Eur Geriatr Med 2010 Feb 01;1(1):9-14. [doi: 10.1016/j.eurger.2009.12.002]

23. Gurwitz JH, Field TS, Harrold LR, Rothschild J, Debellis K, Seger AC, et al. Incidence and preventability of adverse drug events among older persons in the ambulatory setting. J Am Med Assoc 2003 Mar 5;289(9):1107-1116. [Medline: 12622580]

24. Garg AX, Adhikari NK, McDonald H, Rosas-Arellano MP, Devereaux PJ, Beyene J, et al. Effects of computerized clinical decision support systems on practitioner performance and patient outcomes: a systematic review. J Am Med Assoc 2005 Mar 9;293(10):1223-1238. [doi: 10.1001/jama.293.10.1223] [Medline: 15755945]

25. Lau F, Kuziemsky C, Price M, Gardner J. A review on systematic reviews of health information system studies. J Am Med Inform Assoc 2010;17(6):637-645 [FREE Full text] [doi: 10.1136/jamia.2010.004838] [Medline: 20962125]

26. Lau F, Price M, Boyd J, Partridge C, Bell H, Raworth R. Impact of electronic medical record on physician practice in office settings: a systematic review. BMC Med Inform Decis Mak 2012 Feb 24;12:10 [FREE Full text] [doi: 10.1186/1472-6947-12-10] [Medline: 22364529]

27. Tamblyn R, Huang A, Taylor L, Kawasumi Y, Bartlett G, Grad R, et al. A randomized trial of the effectiveness of on-demand versus computer-triggered drug decision support in primary care. J Am Med Inform Assoc 2008;15(4):430-438 [FREE Full text] [doi: 10.1197/jamia.M2606] [Medline: 18436904]

28. Ash JS, Berg M, Coiera E. Some unintended consequences of information technology in health care: the nature of patient care information system-related errors. J Am Med Inform Assoc 2004 Apr;11(2):104-112 [FREE Full text] [doi: $\underline{10.1197 / j a m i a . M 1471]}$ [Medline: 14633936]

29. Yu P, Zhang Y, Gong Y, Zhang J. Unintended adverse consequences of introducing electronic health records in residential aged care homes. Int J Med Inform 2013 Sep;82(9):772-788. [doi: 10.1016/j.ijmedinf.2013.05.008] [Medline: 23770027]

30. Sittig DF, Wright A, Osheroff JA, Middleton B, Teich JM, Ash JS, et al. Grand challenges in clinical decision support. J Biomed Inform 2008 Apr;41(2):387-392 [FREE Full text] [doi: 10.1016/j.jbi.2007.09.003] [Medline: 18029232]

31. Middleton B, Bloomrosen M, Dente MA, Hashmat B, Koppel R, Overhage JM, American Medical Informatics Association. Enhancing patient safety and quality of care by improving the usability of electronic health record systems: recommendations from AMIA. J Am Med Inform Assoc 2013 Jun;20(e1):e2-e8 [FREE Full text] [doi: 10.1136/amiajnl-2012-001458] [Medline: 23355463]

32. Sittig DF, Ash JS, Singh H. The SAFER guides: empowering organizations to improve the safety and effectiveness of electronic health records. Am J Manag Care 2014 May;20(5):418-423 [FREE Full text] [Medline: 25181570]

33. Weiskopf NG, Weng C. Methods and dimensions of electronic health record data quality assessment: enabling reuse for clinical research. J Am Med Inform Assoc 2013 Jan 1;20(1):144-151 [FREE Full text] [doi: 10.1136/amiajnl-2011-000681] [Medline: 22733976]

34. McCormack JL, Ash JS. Clinician perspectives on the quality of patient data used for clinical decision support: a qualitative study. AMIA Annu Symp Proc 2012;2012:1302-1309 [FREE Full text] [Medline: 23304409]

35. Giguere A, Labrecque M, Grad R, Cauchon M, Greenway M, Légaré F, et al. Barriers and facilitators to implementing Decision Boxes in primary healthcare teams to facilitate shared decisionmaking: a study protocol. BMC Med Inform Decis Mak 2012 Aug 06;12:85 [FREE Full text] [doi: 10.1186/1472-6947-12-85] [Medline: 22867107]

36. Price M, Weber J, McCallum G. SCOOP - The Social Collaboratory for Outcome Oriented Primary Care. : IEEE; 2014 Presented at: IEEE International Conference on Healthcare Informatics (ICHI); 2014; Verona p. 210. [doi: 10.1109/ICHI.2014.36]

37. Halekoh U, Højsgaard S, Yan J. The R package geepack for generalized estimating equations. J Stat Soft 2006;15(2). [doi: 10.18637/jss.v015.i02]

38. Wagner MM, Hogan WR. The accuracy of medication data in an outpatient electronic medical record. J Am Med Inform Assoc 1996;3(3):234-244 [FREE Full text] [Medline: $\underline{8723614]}$

39. Cohen B, Vawdrey DK, Liu J, Caplan D, Furuya EY, Mis FW, et al. Challenges associated with using large data sets for quality assessment and research in clinical settings. Policy Polit Nurs Pract 2015 Aug;16(3-4):117-124 [FREE Full text] [doi: 10.1177/1527154415603358] [Medline: 26351216]

40. Walker KL, Kirillova O, Gillespie SE, Hsiao D, Pishchalenko V, Pai AK, et al. Using the CER Hub to ensure data quality in a multi-institution smoking cessation study. J Am Med Inform Assoc 2014;21(6):1129-1135 [FREE Full text] [doi: 10.1136/amiajnl-2013-002629] [Medline: 24993545]

41. Sukumar SR, Natarajan R, Ferrell RK. Quality of Big Data in health care. Int J Health Care Qual Assur 2015;28(6):621-634. [doi: 10.1108/IJHCQA-07-2014-0080] [Medline: 26156435]

42. Price M, Lau F. The clinical adoption meta-model: a temporal meta-model describing the clinical adoption of health information systems. BMC Med Inform Decis Mak 2014 May 29;14:43 [FREE Full text] [doi: 10.1186/1472-6947-14-43] [Medline: 24884588]

43. Berner ES, Kasiraman RK, Yu F, Ray MN, Houston TK. Data quality in the outpatient setting: impact on clinical decision support systems. AMIA Annu Symp Proc 2005:41-45 [FREE Full text] [Medline: 16778998] 
44. Price M, Singer A, Kim J. Adopting electronic medical records: are they just electronic paper records? Can Fam Physician 2013 Jul;59(7):e322-e329 [FREE Full text] [Medline: 23851560]

45. Weber JH, Price M, Davies I. Taming the data quality dragon--a theory and method for data quality by design. Stud Health Technol Inform 2015;216:928. [Medline: 26262230]

46. Price M, Weber JH, Davies I, Bellwood P. Lead user design: medication management in electronic medical records. Stud Health Technol Inform 2015;216:237-241. [Medline: 26262046]

\section{Abbreviations}

CDS: clinical decision support

CDSS: clinical decision support system

COPD: Chronic Obstructive Pulmonary Disease

DQ: data quality

ICD: International Classification of Disease

EMR: electronic medical record

PIP: potentially inappropriate prescriptions

RCT: randomized controlled trial

STOPP: screening tool of older people's prescriptions

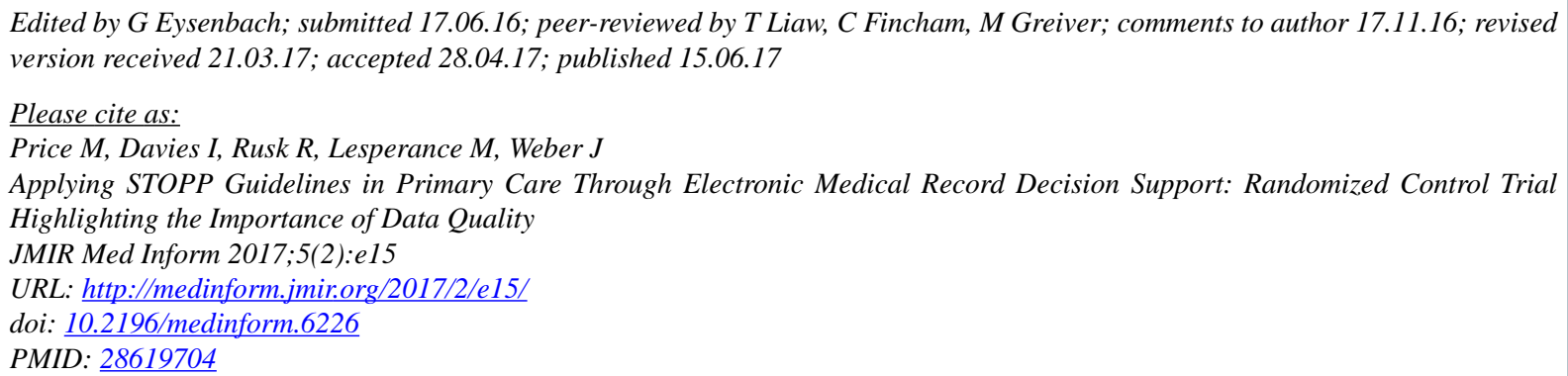

CMorgan Price, Iryna Davies, Raymond Rusk, Mary Lesperance, Jens Weber. Originally published in JMIR Medical Informatics (http://medinform.jmir.org), 15.06.2017. This is an open-access article distributed under the terms of the Creative Commons Attribution License (https://creativecommons.org/licenses/by/4.0/), which permits unrestricted use, distribution, and reproduction in any medium, provided the original work, first published in JMIR Medical Informatics, is properly cited. The complete bibliographic information, a link to the original publication on http://medinform.jmir.org/, as well as this copyright and license information must be included. 